\title{
Charcoal does not change the decomposition rate of mixed litters in a mineral cambisol: a controlled conditions study
}

\author{
Abiven, S ; Andreoli, R
}

\begin{abstract}
It has been recently shown that the presence of charcoal might promote humus decomposition in the soil. We investigated the decomposition rate of charcoal and litters of different biochemical quality mixed together in a soil incubation under controlled conditions. Despite the large range of organic substrate quality used in this study, we did not find any difference in the decomposition between the average of two individual substrates decomposing separately and the same substrates mixed together. We concluded that charcoal does not always promote other organic matter decomposition and that its particular effect might depend on various factors, for example, soil properties.
\end{abstract}

DOI: https://doi.org/10.1007/s00374-010-0489-1

Posted at the Zurich Open Repository and Archive, University of Zurich ZORA URL: https://doi.org/10.5167/uzh-39720

Journal Article

Published Version

Originally published at:

Abiven, S; Andreoli, R (2011). Charcoal does not change the decomposition rate of mixed litters in a mineral cambisol: a controlled conditions study. Biology and Fertility of Soils, 47(1):111-114.

DOI: https://doi.org/10.1007/s00374-010-0489-1 


\title{
Charcoal does not change the decomposition rate of mixed litters in a mineral cambisol: a controlled conditions study
}

\author{
Samuel Abiven • Romano Andreoli
}

Received: 6 April 2010 /Revised: 13 July 2010 /Accepted: 21 July 2010/Published online: 3 August 2010

(C) Springer-Verlag 2010

\begin{abstract}
It has been recently shown that the presence of charcoal might promote humus decomposition in the soil. We investigated the decomposition rate of charcoal and litters of different biochemical quality mixed together in a soil incubation under controlled conditions. Despite the large range of organic substrate quality used in this study, we did not find any difference in the decomposition between the average of two individual substrates decomposing separately and the same substrates mixed together. We concluded that charcoal does not always promote other organic matter decomposition and that its particular effect might depend on various factors, for example, soil properties.
\end{abstract}

Keywords Charcoal $\cdot$ Mixed substrates decomposition . Incubation

\section{Introduction}

Fire-derived charcoal decomposability has been lately intensively discussed in the literature (Preston and Schmidt 2006; Czimczik and Masiello 2007). Until recently, it was thought recalcitrant in the soil with an average turnover of thousands of years, and as a consequence, became an ideal candidate for carbon (C)

Authors' contribution Samuel Abiven designed the experimental setup, took part in the experiment installation and monitoring, analysed the data and wrote the manuscript. Romano Andreoli prepared the experimental design and analysed most of the samples.

S. Abiven $(\bowtie) \cdot R$. Andreoli

Unit of Soil Science and Biogeography, Physical Geography,

Department of Geography, University of Zurich,

Zurich, Switzerland

e-mail: samuel.abiven@geo.uzh.ch sequestration in the soil (Kuhlbusch 1998); however, a series of recent publications (Hammes et al. 2008; Zimmerman 2010) proposed much shorter turnover $(<500$ years) and even suggested a positive priming effect of charcoal on the soil organic matter (Blagodatskaya and Kuzyakov 2008; Kuzyakov et al. 2009; Hamer et al. 2004).

In a recent article, Wardle et al. (2008) observed that fire-derived charcoal caused loss of forest humus, in a 10year-litter-bags experiment. The mass balance of a charcoal and humus mixture was compared to the mass loss of humus and charcoal considered individually. Positive interactions between charcoal and glucose on the mixture degradation have been already reported (Hamer et al. 2004). However, the reasons of these interactions are virtually unknown and the actual role of charcoal in these interactions is still under debate (Lehmann and Sohi 2008). In particular, it is not obvious if it is the degraded litter or the charcoal that positively influence the decomposition of the mixture.

The decomposition of mixed substrates is not always predictable from single-species decomposition dynamics. Gartner and Cardon (2004) reviewed studies which reported these interactions. In the majority of studies, a synergistic effect was observed (i.e. the degradation of the mixture is greater than the sum of the two-litter degradation considered separately). However, the interaction could be antagonistic (the mixture decomposes less than the two litters) or even additive (no difference between the mixture and the sum of the individual litters).

One hypothesis to explain these synergistic effects is the overall litter quality improvement of a poorly degradable organic matter by a high-quality substrate. For example, nitrogen-depleted organic product decomposition can be improved by being mixed with an N-rich substrate (Wardle 
et al. 1997). Also, microbial communities developing after the addition of a high-quality residue might collaterally decompose the low-quality substrate. On the other hand, secondary chemical compounds like polyphenol can decrease the decomposition rate of an organic substrate (Palm and Sanchez 1990; Nilsson et al. 1998). The transfer of such compounds from one substrate decomposition area to another could explain the antagonistic effect on the decomposition of a mixture.

Charcoal is aromatic in nature, chemically highly condensed and poor in nitrogen. It is also considered as very recalcitrant. Therefore, there is an apparent paradox between the recent findings by Wardle et al. (2008) and the potential synergistic effect of charcoal.

We tested the hypothesis of synergistic and antagonistic effects on the decomposition of wood and charcoal in mixture with various organic substrates of contrasting quality under controlled conditions.

\section{Material and methods}

The soil used was a cambisol with $30 \%$ clay, $4 \%$ organic C and $\mathrm{pH}$ 6.1. It was sampled within the first $15 \mathrm{~cm}$ from the surface of an experimental field in Aargau (Switzerland). The soil was sampled at the end of September in an undisturbed 15-year-old windthrow area of a deciduous forest. The soil was bare (no plant at the emplacement of the sampling and no visible litter layer left from the previous year). It was sieved fresh $(<2 \mathrm{~mm})$ and preincubated at $20^{\circ} \mathrm{C}$ for 14 days.

Six different organic substrates were used in this study: spruce stem wood (Picea abies) and charcoal produced from this wood were mixed respectively to alder leaves (Aldus glutinosa), ash leaves (Fraxinus excelsior), spruce needles and oak bark (Quercus robur), chosen in order to display a large range of substrate quality. The charcoal was produced at $450^{\circ} \mathrm{C}$ for $5 \mathrm{~h}$ under $\mathrm{N}_{2}$ according to the procedure proposed by Hammes et al. (2006). Each organic substrate was dried at $40^{\circ} \mathrm{C}$ and grounded to $<1 \mathrm{~mm}$ particle size. Carbon and $\mathrm{N}$ was measured using an elemental analyser. The polyphenol content was estimated by water extraction $(100 \mathrm{mg}$ of organic substrate in $15 \mathrm{~mL}$ of water) for $1 \mathrm{~h}$ and measurement by colorimetry using Folin-Denis reagent for the coloration (read at $725 \mathrm{~nm}$ ) and solutions of p-hydroxy-benzo acid used for the calibration. The $\mathrm{pH}$ of the charcoal was 4.3 , which is consistent with previous observations made on lab-produced charcoals (Abiven, personal communication). Also, the final soil $\mathrm{pH}$ of the various treatments was not significantly different from the beginning of the experiment and within the treatments (data not shown).
Substrate particles were incorporated homogeneously to $60 \mathrm{~g}$ of fresh soil at a rate of $25 \mathrm{~g}$ of $\mathrm{C}$ per kilogram of dry soil into $2-\mathrm{L}$ glass jars and incubated at constant temperature $\left(24^{\circ} \mathrm{C}\right)$ and moisture (field capacity) for 240 days. The jars were opened regularly in order to keep aerobic conditions. Each organic substrate was incubated individually. Subsequently, the spruce wood and the charcoal were incubated mixed with each of the four other substrates at 1:1 C percent ratio. Together with these treatments, a soil without amendment was incubated and used as a control and empty jars were kept as blanks. Each treatment was replicated three times.

The $\mathrm{CO}_{2}$ in the jars was trapped in $20 \mathrm{~mL}$ of $1 \mathrm{M}$ $\mathrm{NaOH}$ and was assessed by conductivity 16 times over the study period according to the method described by Wollum and Gomez (1970) and used recently by Hagedorn et al. (2005). The method was validated previously on calibrated $\mathrm{NaOH}$ solutions (data not shown). The observed data, i.e. the $\mathrm{CO}_{2}$ measured from the mixed substrates, was then compared to the expected values, i.e. the average of the $\mathrm{CO}_{2}$ measured from the substrates incubated individually. The $\mathrm{CO}_{2}$ values are presented as the cumulative average of the three replicates. Blank and control values were subtracted in order to display specifically the effect of the organic substrate mixtures.

\section{Results and discussion}

The four substrates added in mixture to the charcoal and spruce wood displayed a large range of chemical quality (Table 1) and represented four distinctive situations: high-N and high-polyphenol contents (Alder leaves), high-N and low-polyphenol contents (Ash leaves, higher litter quality), low-N and high-polyphenol content (Oak bark, lower litter quality) and relatively low-N and low-polyphenol contents (Spruce needles). Charcoal and spruce wood were both low in polyphenol and $\mathrm{N}$.

Despite the large range of substrate quality in the mixture, we found additive decomposition rates in seven of the eight mixtures after 240 days of incubation (Fig. 1). The exception was the mixture between ash leaves and charcoal where a small but significant antagonistic effect was observed at the end of the incubation. We also observed a strict additive effect along the mixture decomposition. We only identified a significant synergistic effect in the mixture between ash leaves and spruce wood, but this effect was not significant beyond 40 days.

Using a different experimental setup (laboratory incubation vs field) and another method to estimate the decomposition $\left(\mathrm{CO}_{2}\right.$ trapping vs litter-bag mass loss), our results 
Fig. 1 Cumulative $\mathrm{CO}_{2}$ mineralisation (expressed as $\mathrm{C} \%$ of $\mathrm{C}$ initially added) for char (square symbols) and wood (circle symbols) mixed with alder leaves (a), ash leaves (b), spruce needles (c) and oak bark (d). The full symbols represent the observed values (incubated mixture) and the empty symbols represent the expected values (average value calculated from the data of two substrates incubated separately). Bars indicate standard errors $(n=3)$
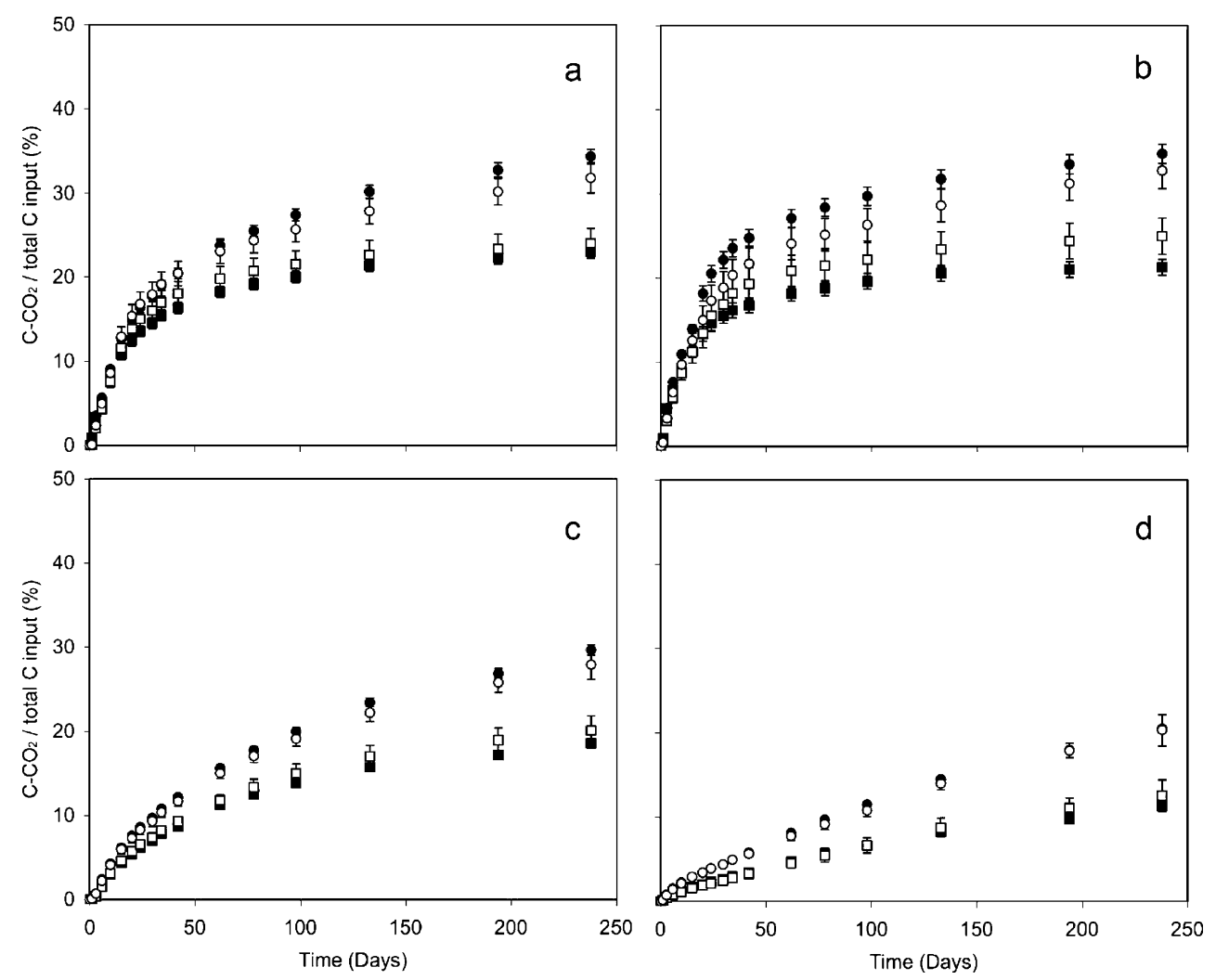

challenge the results published by Wardle et al. (2008). In our study, the charcoal did not enhance the decomposition of the mixture and even decreased the decay rate in one of the case. Different reasons could explain this discrepancy. First, our experimental setup ran on a shorter term (240 days vs 10 years). However, in the litter-bag study, most of the changes occurred during the first year period which should be covered by this incubation. Second, we measured the decomposition rate by following the $\mathrm{C}$ dynamics while earlier study was based on the mass loss. With litter bags, it is possible that mass losses are due to soluble compounds carried away by water or losses of humus particles smaller than the mesh size of the bag. Third, we used the first mineral horizon of a cambisol rather than an organic layer, so the decomposition conditions were quite different in both studies.

Our results also diverged from the litter quality improvement proposed as one of the explanation hypothesis by
Gartner and Cardon (2004). Despite the large range of litter quality we used, we observed additive effects in most of the cases. If our results do not prove that the litter quality improvement is not relevant, they show that decomposition conditions do matter. In particular, the soil properties might be driving the interactions between the two substrates. In our experimental setup, there were no water movement and so potentially less transfer of nitrogen of polyphenol from one substrate to another. Also, the soil we used was rich in organic matter and so the eventual quality improvement might be buffered by the large pool of organic compounds into the soil.

Our study points out that no generalisation can be made on charcoal role on litter decomposition. A future research need will be to understand better in which context charcoal is influencing organic matter decomposition, in particular, by studying different soils with various properties.
Table 1 Chemical characteristics of the six organic substrates

$n s$ not significant

\begin{tabular}{lcccc}
\hline & C percent & N percent & C:N ratio & Polyphenols $\left(\mathrm{g} \mathrm{kg}^{-1}\right)$ \\
\hline Spruce wood & 45.9 & 0.17 & 263.6 & $31.3 \pm 0.3$ \\
Charcoal & 70.7 & 0.5 & 140.4 & $\mathrm{~ns}$ \\
Alder leaves & 47.5 & 2.45 & 19.4 & $108.4 \pm 0.8$ \\
Ash leaves & 44.4 & 2.22 & 19.9 & $34.5 \pm 0.5$ \\
Spruce needles & 48.8 & 1.21 & 40.2 & $81.3 \pm 1.6$ \\
Oak bark & 46.7 & 0.49 & 96.2 & $129.2 \pm 2.8$ \\
\hline
\end{tabular}


Acknowledgements The authors thank Bruno Kägi, Michael Hilf, Ivan Woodhatch and Pascal Hentgarner for the technical assistance; Michael W.I. Schmidt for the discussions while preparing the experimentation; and the "reading group" for the comments on the manuscript. The authors also acknowledge the inputs of the anonymous reviewers.

\section{References}

Blagodatskaya E, Kuzyakov Y (2008) Mechanisms of real and apparent priming effects and their dependence on soil microbial biomass and community structure: critical review. Biol Fertil Soils 45:115-132

Czimczik CI, Masiello CA (2007) Controls on black carbon storage in soils. Global Biogeochem Cycles 21. doi:10.1029/2006GB002798

Gartner TB, Cardon ZG (2004) Decomposition dynamics in mixedspecies leaf litter. Oikos 104:230-246

Hagedorn F, Maurer S, Bucher JB, Siegwolf RTW (2005) Immobilization, stabilization and remobilization of nitrogen in forest soils at elevated $\mathrm{CO}_{2}: \mathrm{a}{ }^{15} \mathrm{~N}$ and ${ }^{13} \mathrm{C}$ tracer study. Glob Chang Biol 11:1816-1827

Hamer U, Marschner B, Brodowski S, Amelung W (2004) Interactive priming of black carbon and glucose mineralisation. Org Geochem 35:823-830

Hammes K, Smernik RJ, Skjemstad JO, Herzog A, Vogt UF, Schmidt MWI (2006) Synthesis and characterisation of laboratory-charred grass straw (Oryza sativa) and chestnut wood (Castanea sativa) as reference materials for black carbon quantification. Org Geochem 37:1629-1633
Hammes K, Torn MS, Lapenas AG, Schmidt MWI (2008) Centennial black carbon turnover observed in a Russian steppe soil. Biogeosciences 5:1339-1350

Kuhlbusch TAJ (1998) Black carbon and the carbon cycle. Science 280:1903-1904

Kuzyakov Y, Subbotina I, Chen H, Bogomolova I, Xu X (2009) Black carbon decomposition and incorporation into soil microbial biomass estimated by 14C labeling. Soil Biol Biochem 41:210 219

Lehmann CJ, Sohi SP (2008) Comment on "Fire-derived charcoal causes loss of forest humus". Science 321(5894):1295

Nilsson MC, Gallet C, Wallstedt A (1998) Temporal variability of phenolics and batatasin-III in Empetrum hermaphroditum leaves over an eight-year period: interpretations of ecological function. Oikos 81:6-16

Palm CA, Sanchez PA (1990) Decomposition and nutrient release patterns of the leaves of three tropical legumes. Biotropica 22:330-338

Preston CM, Schmidt MWI (2006) Black (pyrogenic) carbon: a synthesis of current knowledge and uncertainties with special consideration of boreal regions. Biogeosciences 3:397-420

Wardle DA, Nilsson MC, Zackrisson O (2008) Fire-derived charcoal causes loss of forest humus. Science 320:629

Wardle DA, Bonner KI, Nicholson KS (1997) Biodiversity and plant litter: experimental evidence which does not support the view that enhanced species richness improves ecosystem function. Oikos 79:247-258

Wollum AG, Gomez JE (1970) A conductivity method for measuring microbially evolved carbon dioxide. Ecology 51:155-156

Zimmerman AR (2010) Abiotic and microbial oxidation of laboratoryproduced black carbon (biochar). Envir Science Technol 44 (4):1295-1301 